\title{
Preparation and Compressive Properties of Magnesium Foam
}

\author{
Liao Yilong, Qiu Guibao, Yang Yang, Lv Xuewei, Bai Chenguang
}

Chongqing University, Chongqing 400044, China

\begin{abstract}
As a new structural and functional material, metal foam has been proven to obtain excellent properties when compared with dense ones. In the present paper, the powder metallurgy with a space holder technique was used to prepare magnesium foam. The porosity of the foam ranges from $38.90 \%$ to $57.50 \%$, when the elastic modulus decreases from $8.50 \mathrm{GPa}$ to $3.30 \mathrm{GPa}$, and the initial yield stress decreases from 24.90 MPa to 9.40 MPa. The magnesium foam has lower yield stress and longer stress platform, so it can be used as good cushioning energy absorbing materials.
\end{abstract}

Key words: magnesium foam; yield stress; elastic modulus; energy absorption property

As a new type structure and functional materials, porous materials have better properties than solid materials, which broaden the fields of research and application of foam materials ${ }^{[1-3]}$. Magnesium metal has a lot of advantages, such as specific strength, stiffness, high modulus elastic, good defense noise and excellent vibration reducing performance. The density of pure magnesium is $1.74 \mathrm{~g} / \mathrm{cm}^{3}$, which is the lightest metal in industrial applications. Magnesium foam can absorb energy because of its specific structure. Compared with foamed plastics, foamed metal has a higher melting point, high-temperature stability, better weather fastness and harder ageing ${ }^{[4,5]}$. In addition foamed metal has better vibration resistance, more convenient installation, disassembly and other excellent properties compared with foamed ceramics ${ }^{[6-8]}$. Therefore, studying the compression deformation behavior and energy absorption property of magnesium foam is very significant.

Metal foam is widely used in brakes and shock absorber of automobiles. As the structural material of impact energy absorbing, it can improve vehicle vibration and collision safety of automobiles ${ }^{[9,10]}$. The closed-cell magnesium foam was prepared and its static compressive properties were studied by Yong etc, and they found that the porosity of magnesium foam increases from $53.0 \%$ to $71.10 \%$, resulting in the yield strength decreasing from 27.1 MPa to 4.2 $\mathrm{MPa}$ and the energy absorb decreasing from $12.7 \mathrm{MJ} / \mathrm{m}^{3}$ to $4.2 \mathrm{MJ} / \mathrm{m}^{3}{ }^{[11]}$. The magnesium foam with $40 \% \sim 50 \%$ porosity was prepared by Sun etc, with potassium bicarbonate as a foaming agent, the aperture of $100 \sim 200$ $\mu \mathrm{m}$, and the deposition of calcium phosphate coating on the surface of the magnesium substrate in order to enhance corrosion resistance of the matrix ${ }^{[12]}$. Magnesium foam alloy was prepared successfully using vacuum filtration by Li et al, and static compressive properties of magnesium foam alloy was studied under the static load ${ }^{[13]}$. Over half of metal foam research fixes on aluminum foam and its alloy. However, research on the metal foam material is very later. In addition, the preparation process and the process parameters have a great influence on the structure, which affects the performance, but the detailed mechanism in the process has not been studied systematically. In the present work, powder metallurgy with a space holder technique was used to prepare magnesium foam materials in order to obtain good energy absorption of magnesium foam, which can be applied to shock absorber so that it improves the safety and steady of automobiles.

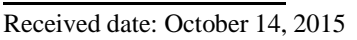

Foundation item: National Natural Science Foundation of China (51174243, 51090383)

Corresponding author: Qiu Guibao, Ph. D., Associate Professor, College of Materials Science and Engineering, Chongqing University, Chongqing 400044, P. R. China, Tel: 0086-23-65111256, E-mail: qiuguibao@cqu.edu.cn 


\section{Experiment}

The powder metallurgy with a space holder technique was used to prepare magnesium foam. Commercial, magnesium powder (purity $\geq 99.5 \%$, particle size $50 \sim 75 \mu \mathrm{m}$ ) and carbamide particle (purity $\geq 99.5 \%$, particle size $1.1 \sim 1.2$ $\mathrm{mm}$ ) were used as raw materials. Carbamide as raw material can hold spaces of pores at lower temperature and decompose completely at $400{ }^{\circ} \mathrm{C}$ so as to avoid the reaction with the magnesium powder. The SEM images of space holder and magnesium powder are showed in Fig.1. The mechanical properties of magnesium foam are mainly affected by the structure of pores, and the particle sizes of raw materials directly influences the pore structure of magnesium foam. In addition, adding a little absolute ethanol as dispersing agent can get homogeneous blend materials.

The processing of preparing magnesium foam can be seen in Fig.2. The mainly steps contain computation ingredient, mixing, compacting and heat treatment. Firstly, the powders of magnesium and carbamide were mixed proportionally for $15 \mathrm{~min}$ in an agate mortar. After blending the ingredients well, the powders of the mixture were uniaxially pressed at $200 \mathrm{MPa}$ for $1 \mathrm{~min}$ to transmit the pressure sufficiently and avoid the bridging effect. Then the samples were heat-treated by argon gas protection. ZT-25-20 vacuum carbon tube furnace as experimental equipment is shown in Fig.3. The vacuum degrees can reach to $10^{-2} \mathrm{~Pa}$. The main factors need to be taken into consideration, which include evaporation of water,

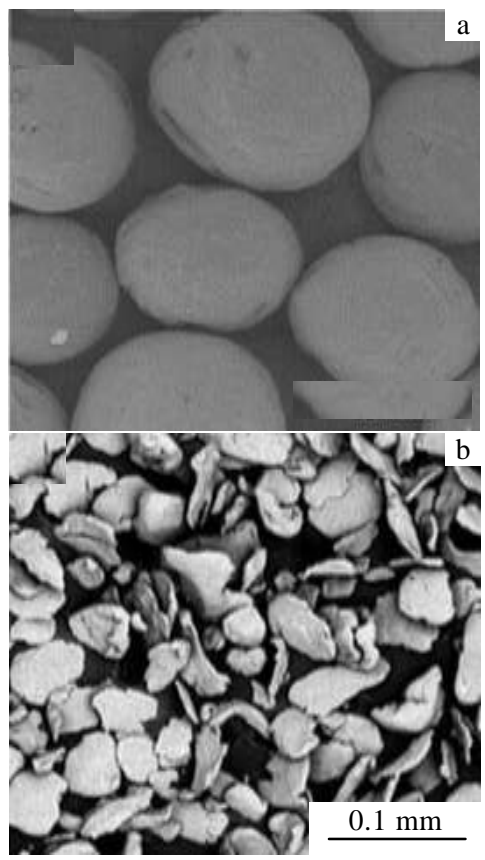

Fig.1 Morphologies of raw materials of carbamide (a) and magnesium powder (b) decomposition of urea and the sintering of powder.

Fig. 4 shows the differential thermal curve of carbamide. It can be seen easily that carbamide begins to decompose at $160{ }^{\circ} \mathrm{C}$ and stops decomposing at $400{ }^{\circ} \mathrm{C}$. Temperature curves of sintering is shown in Fig.5. The heating rate is $10{ }^{\circ} \mathrm{C} / \mathrm{min}$ below $160{ }^{\circ} \mathrm{C}$, and $5{ }^{\circ} \mathrm{C} / \mathrm{min}$ in $160 \sim 400{ }^{\circ} \mathrm{C}$ to avoid sample collapse. And sintering consisted of two steps, at $400{ }^{\circ} \mathrm{C}$ for $1 \mathrm{~h}$ and $630{ }^{\circ} \mathrm{C}$ for $2 \mathrm{~h}$. After natural cooling, we got the needed magnesium foam.

\section{Results and Discussion}

\subsection{Compressive properties}

Mechanical properties of the magnesium foams were studied by compression tests. Fig.6 shows the topography of compressed magnesium foam with different porosity.

Samples with different porosity were compressed, and the results show they are different in height. The metal foam deformation behavior as shown in Fig.7, mainly include three steps: linear elastic, collapse and densification.

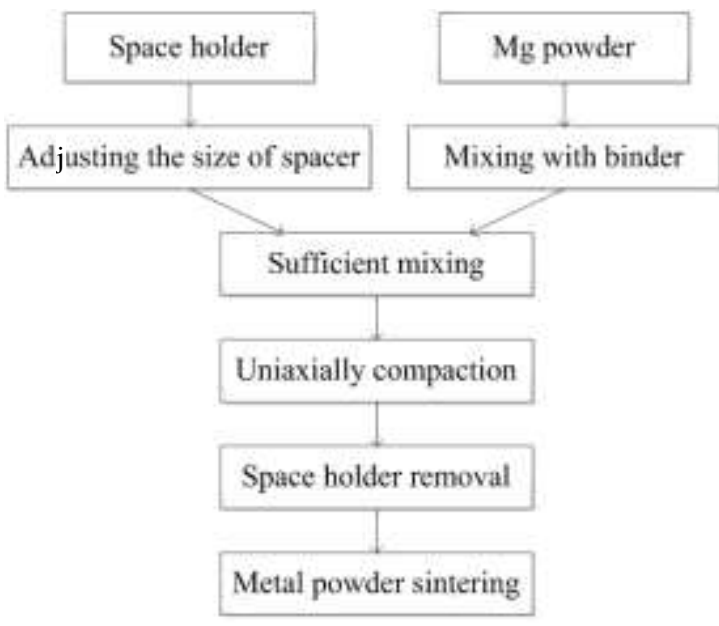

Fig.2 Processing of powder metallurgy using space holder technique

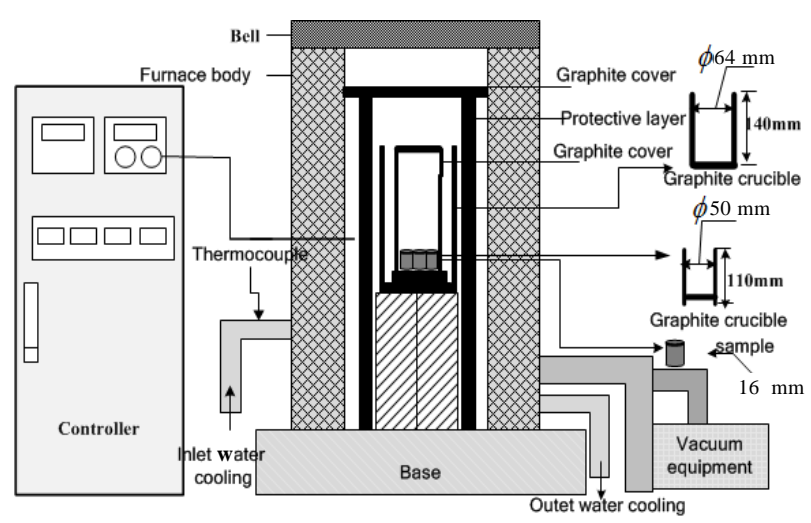

Fig.3 Experimental equipment of sintering 


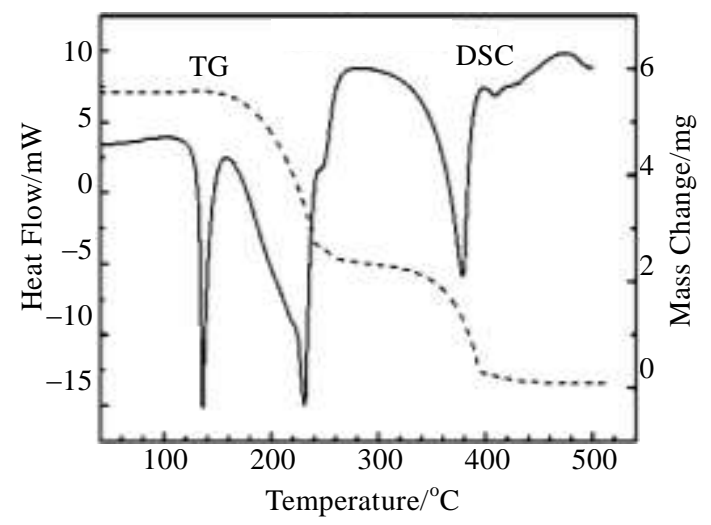

Fig.4 Differential thermal curves of the carbamide

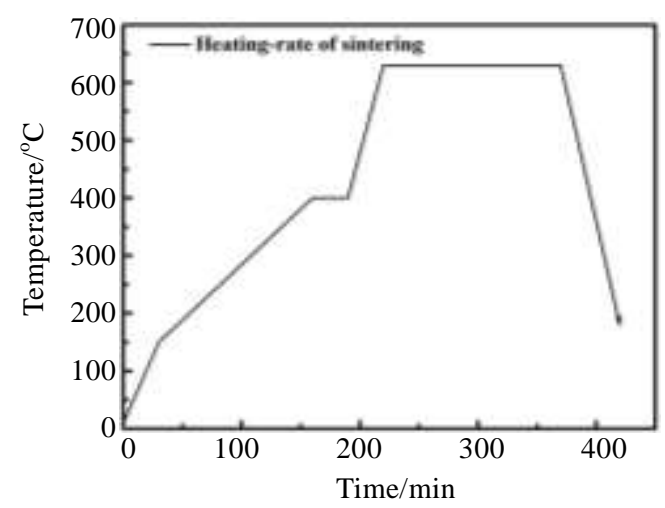

Fig.5 Time vs temperature for heat-treatment
The stress-strain curves of magnesium foam with various porosity are shown in Fig.8. The three curves of magnesium foam samples show very similar universal characteristics of metallic foam, for instance, an elastic deformation stage at the beginning of deformation, a long plateau stage with a nearly constant low stress to large strain, and a densification stage where the limit stress rapidly increases.

According to the Gibson-Ashby model, the most important structural characteristic of metal foam influencing the elastic modulus $E$ is its relative density, $\rho / \rho_{\mathrm{s}}$ (the density of the foam is $\rho$, the density of solid material is $\rho_{\mathrm{s}}$ ). For the open -cellular metal foam, the elastic modulus relationship with relative density is as follows:

$$
E / E_{\mathrm{s}}=C\left(\rho / \rho_{\mathrm{s}}\right)^{2}
$$

where, $E$ is the elastic modulus of metal foam, $E_{\mathrm{s}}$ is the elastic modulus of solid metal, and $C$ is a constant of about 1. However, the relative density relationship with porosity is

$$
p=1-\rho / \rho_{\mathrm{s}}
$$

The effect of the porosity on the elastic modulus of magnesium foam is shown in Fig.9. When the porosity increases from $38.90 \%$ up to $57.70 \%$, the elastic modulus decreases from $8.50 \mathrm{GPa}$ to $3.30 \mathrm{GPa}$. The red points are from the experimental data, and the black points are from the theoretical calculation by Gibson-Ashby Eq.(1). The elastic modulus decreases with the increasing of the porosity, and both the lines of the calculated and the experimental reveal the same tendency.

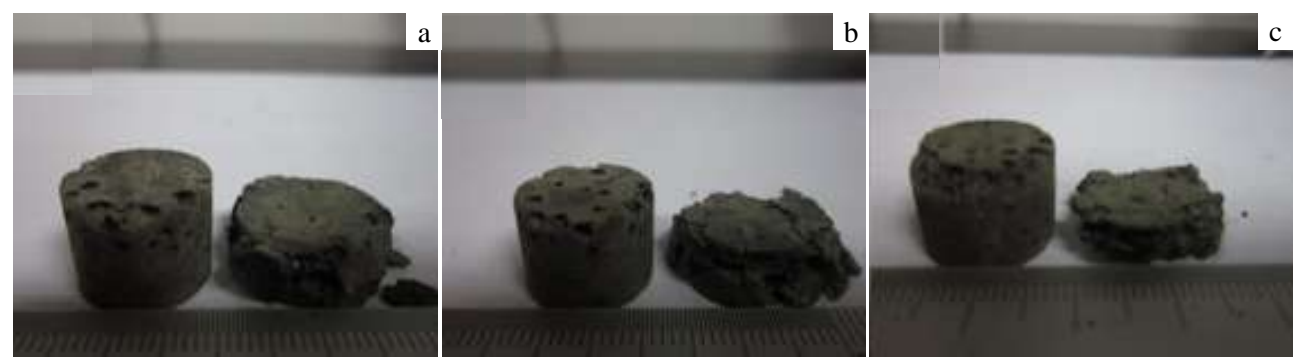

Fig.6 Topography of compressed magnesium foam with different porosity

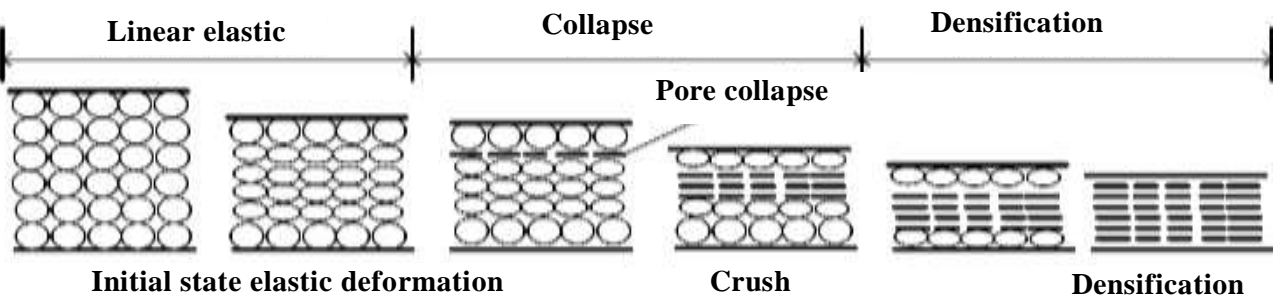

Fig.7 Typical deformation mechanism of metal foam 


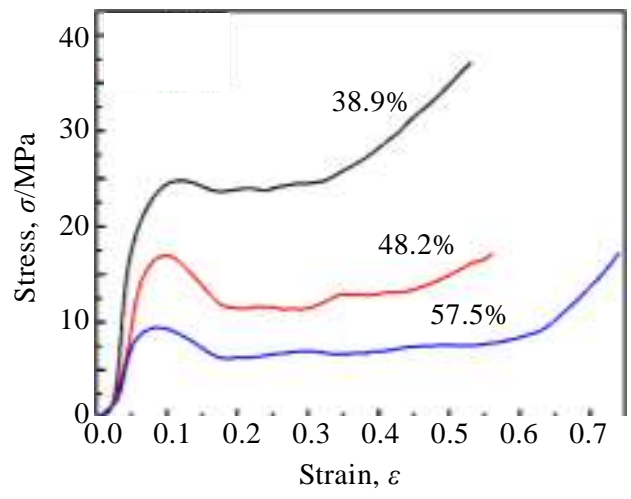

Fig.8 Stress-strain curves of magnesium foam with different porosity

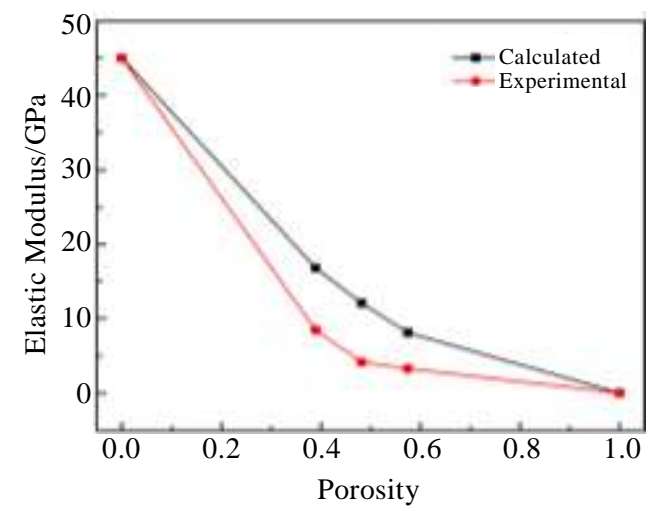

Fig.9 Effect of the porosity on the elastic modulus of magnesium foam

The initial yield stress of magnesium foam with different porosity is shown in Table 1 . The porosity increases from $38.90 \%$ up to $57.70 \%$, and the yield stress decreases from $24.90 \mathrm{MPa}$ to $9.40 \mathrm{MPa}$.

\subsection{Energy absorption}

Metal foam has good shock-resistant and excellent energy absorption property. Energy absorption capacity metal foam was measured by compressive crush. Based on the serrations of the stress-strain curve, energy absorption capacity is equal to the area between the stress-strain curve and the horizontal axis up to densification ${ }^{[14]}$. It is important to calculate energy absorption capacity of magnesium foam with different porosity.

Ideal energy absorption curve of metal foam is shown in Fig.10. The energy absorbed per unit volume $(W)$ in deformation of magnesium foam can be written as:

$$
W=\int{ }_{0}^{\varepsilon_{\mathrm{m}}} \sigma(\varepsilon) \mathrm{d} \varepsilon
$$

where, $\sigma(\varepsilon)$ is the stress as a densification of the strain, and $\varepsilon_{\mathrm{m}}$ is the limit strain before densification. Obviously, the higher energy absorption capacity needs the higher the stress
Table 1 Initial yield stress of magnesium foam with different porosity

\begin{tabular}{rccc}
\hline Porosity\% & 38.9 & 48.2 & 57.7 \\
\hline Yield stress/MPa & 24.9 & 17.0 & 9.40 \\
\hline
\end{tabular}

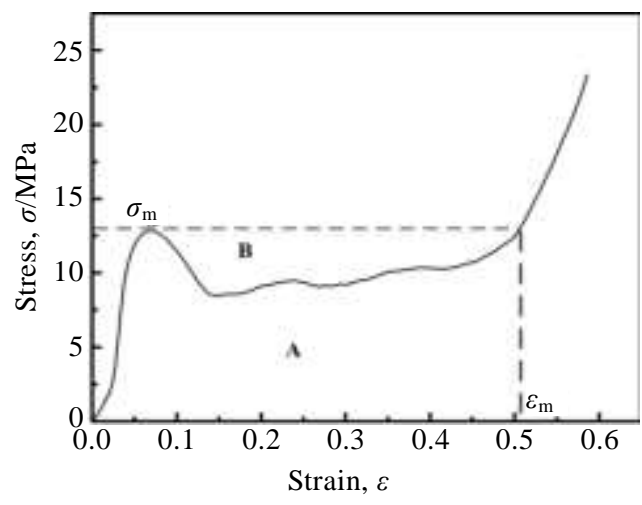

Fig.10 Diagram of ideal energy absorption

plateau. For all the energy absorption materials, if the ratio of $\mathrm{A}$ and $\mathrm{B}$ is bigger, the effect of energy absorption is better, the closer to the ideal energy absorption materials.

According to the criterion of perfect energy absorbed materials, which have lower yield strength and longer stress platform, the goal of protecting objects should be achieved $^{[15]}$. What's more, magnesium foam has lower yield stress and longer stress platform as shown in Fig.10. The energy absorption capacity can be determined according to the stress-strain curve of magnesium foam ${ }^{[16]}$. Therefore, magnesium foam can be used as excellent cushioning energy absorbing materials.

\section{Conclusions}

1) The porosity increases from $38.90 \%$ to $57.50 \%$, when the elastic modulus decreases from $8.50 \mathrm{GPa}$ to $3.30 \mathrm{GPa}$, and the yield stress decreases from 24.90 $\mathrm{MPa}$ to 9.40 MPa.

2) Compared with other metal foam, magnesium foam has lower yield stress and longer stress platform. Therefore, it has good shock-resistant and excellent absorption property.

\section{References}

1 Wen C E, Hosokawa H. Materials Letters[J], 2004, 58(3): 357

2 Czaplicki M J, David C, Kevin H. US Patent, 20040018353 [P], 2004

3 Ashby M F, Lu T J. Science in China Series B: Chemistry [J], 2003, 46(6): 521

4 Martin B, Detlev S, Baur H. Advanced Engineering Materials[J], 2000, 2 (4): 196

5 Gibson L J, Ashby M F. Cellular Solids[M]. Cambridge: Cambridge University Press, 1999

6 Hartmann M, Reindel K, Singer R F. MRS Proceedings[C]. 
San Francisco, CA: AMC, 1998: 211

7 Lefebvre, Louis P, John B et al. Proceedings of the Fifth International Conference on Porous Metals and Metallic Foams [C]. Montreal Ca: PMMF, 2007

8 Li C, Zhang Q M, Xu Z G et al. Acta Armamentarii[J], 2009: S2: 56

9 Staiger M P, Alexis M P, Jerawala $\mathrm{H}$ et al. Biomaterials[J], 2006, 27(9): 1728

10 Lefebvre L P, John B, David D. Advanced Engineering Materials[J], 2008, 10(9): 775

11 Yang H D, Hur B Y, Yang S R. Journal of Alloys and
Compounds[J], 2008, 461(1): 221

12 Sun X H. Thesis for Doctorate[D]. Lanzhou: Lanzhou University of Technology, 2005 (in Chinese)

13 Li Q L. Thesis for Doctorate[D]. Taiyuan: Taiyuan University of Science and Technology, 2009 (in Chinese)

14 Cheng H F, Han F S. Scripta Materialia[J], 2003, 49(6): 583

15 Qiao P Z, Yang M J, Bobaru F. Journal of Aerospace Engineering [J], 2008, 21(4): 235

16 Kou D P, Li J R, Yu J L et al. Scripta Materialia[J], 2008, 59(5): 483

\section{泡沫镁制备及抗压缩性能}

廖益龙, 邱贵宝, 杨 杨, 吕学伟, 白晨光

(重庆大学, 重庆 400044)

摘 要: 作为一种新型结构和功能材料, 泡沫金属具有比实体金属更优异的性能。本研究利用粉末冶金造孔剂法成功制备了孔隙率为 $38.9 \%$ ～57.5\%泡沫镁。随着孔隙率从 $38.9 \%$ 增加到 $57.5 \%$ 时, 其弹性模量由 $8.5 \mathrm{GPa}$ 下降到 $3.3 \mathrm{GPa}$, 初始屈服应力从 $24.90 \mathrm{MPa}$ 下降 到 $9.40 \mathrm{MPa}$ 。泡沫镁具有较低的初始屈服应力和较长的应力平台, 因此, 它可以作为优异的缓冲吸能材料。

关键词：泡沫镁; 屈服应力; 弹性模量；吸能性

作者简介：廖益龙，男，1986 年生，硕士生，重庆大学材料科学与工程学院，重庆 400044，E-mail: liaoylong@ @ina.cn 